\title{
Incivility in online news and Twitter: Effects on attitudes toward scientific topics when reading in a second language
}

\begin{abstract}
On the Internet polite communication can stand side by side with uncivil comments. Research on online incivility has been conducted with users reading in their mother tongues (L1), while the potential effects of incivility in a second language (L2) have been largely underexplored. This paper analyzes the effects of uncivil comments written in an L2 on attitudes around emerging technologies. Study 1 replicates a previous experiment (Anderson et al., 2014) by adding a bilingual condition. Study 2 analyzes the effect of incivility on four fictitious Twitter debates around different scientific issues. Results show that participants usually endorse claims written in civil rather than uncivil manner, but only in their L1.
\end{abstract}

Keywords: incivility; science communication; online deliberation; second language reading; social media; emotional language

\section{Authors}

Agnese Sampietro

University Jaume I, Faculty of Humanities and Social Sciences, Department of European Languages and Cultures, Av. Sos Baynat s/n, 12071 Castellón (Spain), sampietr@uji.es

Ladislao Salmerón 
University of Valencia, Faculty of Psychology, Department of Developmental and Educational Psychology, Research Unit on Reading (ERI Lectura), Av. Blasco Ibáñez 13, 46010 Valencia (Spain), Ladislao.salmeron@uv.es

\section{Corresponding author}

Agnese Sampietro

Universitat Jaume I

Faculty of Humanities and Social Sciences

Department of European Languages and Cultures

Av. Sos Baynat s/n

12071 Castellón de la Plana (Spain)

e-mail: sampietr@uji.es

Phone: +34 964387754

\section{Declaration of interest: None}

\section{Funding}

This work was supported by the Spanish Ministerio de Ciencia, Innovación y Universidades and Agencia Estatal de Investigación (EDU2017-87626-P); and by University Jaume I Postdoctoral Fellowships program (grant POSDOC-A/2017/08). 


\section{Incivility in Online News and Twitter: Effects on Attitudes Toward Scientific}

\section{Topics When Reading in a Second Language}

The advent of the Internet has triggered a real revolution in the way in which information is created, distributed and stored (e.g. Benkler, 2006). One of the characteristics of these new digital scenarios is the amount of information available online and the subsequent need to filter it. Traditionally, the information came from experts or credible sources and was evaluated and filtered before publication. However, due to the participatory nature of Web 2.0 (blogs, discussion forums, wikis, and social networks), a wide variety of actors may create and spread information, without necessarily being experts on a topic.

While the participatory nature of Web 2.0 has the potential to foster deliberation (Dahlgren, 2005; Papacharissi, 2002, 2004), quite often online discussions include offensive comments or replies, which may not only be an impediment to democratic discussion (Sunstein, 2017), but may also influence other people's perceptions of issues and opinions (Anderson, Yeo, Brossard, Scheufele, \& Xenos, 2018; Hwang, Kim, \& Huh, 2014; Popan, Coursey, Acosta, \& Kenworthy, 2019) and affect social influence (Walther et al., 2018). For instance, a large-scale online experiment conducted in the United States found that when faced with incensed comments online, people would rely more on previous beliefs or heuristics around the issue of nanotechnology (Anderson, Brossard, Scheufele, Xenos, \& Ladwig, 2014).

The Internet makes it easier not only to find a wide variety of information and debates on multiple topics but also to easily access content written in a foreign language. Millions of people use foreign languages daily, not only to communicate in a bilingual context or for work, but also to cultivate and to access information (Grosjean, 2010). Indeed, the Internet has highly increased the circulation of news across the globe 
(Reese, 2010; Thurman, 2007; Widholm, 2019). For example, 16\% of subscribers of the English digital edition of the New York Times are from outside the United States (Peiser, 2019). Accordingly, during the last decade, there has been an increased interest in understanding how bilingual people process information and communicate in online scenarios as a function of the language used (their first, L1, or second language, L2) (Salmerón, Abu Mallouh, \& Kammerer, 2017; Tan, Swee, Lim, Detenber, \& Alsagoff, 2008; Tse, Yuen, Loh, Lam, \& Ng, 2010; Walther, Neubaum, Rösner, Winter, \& Krämer, 2018; Yakut \& Aydın, 2017).

Few studies have addressed the effects of reading in an L2 in online discussions. For example, Tan et al. (2008) found that discussants in an online local political forum that wrote in Standard English were considered more authoritative, hence more competent, than those who wrote in Singlish (colloquial Singaporean English). Participants in an experiment by Rösner, Winter, Walther, Krämer, and Ganster (2014) also seemed to pay more attention to comments written in English. This could be one of the reasons why participants in their study did not show in-group identification with comments written in their mother tongue (German) to two anti-marijuana YouTube videos, but rather identified with positive comments written in English. These results were further tested in a subsequent study by Walther et al. (2018), who found that YouTube comments had a greater influence when they matched the language of the video they referred to (English or Mandarin), regardless of the argument used (Walther et al., 2018). In sum, these studies suggest that in bilingual online discussions people may grant English a particular status, and accordingly they may use language per se as heuristic to evaluate online discussions (Tan et al., 2008).

On a different research line, psycholinguistic research has explored the way bilingual people think and reason in an L2. Research converges on the idea that when 
using an L2 bilinguals are less prone to cognitive biases (Costa, Foucart, Arnon, Aparici, \& Apesteguia, 2014; Costa, Foucart, Hayakawa, et al., 2014; Keysar et al., 2012). A possible explanation for this phenomenon is the affective distance towards messages conveyed in an L2 (Costa, Foucart, Arnon, et al., 2014; Geipel, Hadjichristidis, \& Surian, 2015b; Hadjichristidis, Geipel, \& Savadori, 2015). By perceiving affective content less intensely, bilinguals may process the information more deliberately and less automatically in their L2, which could have a positive influence in terms of information evaluation and decision making (Costa, Foucart, Hayakawa, et al., 2014; Keysar et al., 2012). The present study aims to further advance our knowledge of information processing in an L2 in naturalistic scenarios, specifically comments in online news sites and Twitter. The objective of this study is twofold: 1) replicate Anderson's et al. (2014) study about the polarizing effects of uncivil comments in online news' commentaries adding a bilingual condition, in order to explore if the socalled 'nasty effect' exists even when users read information written in a foreign language; 2) extending the analysis of the effects of uncivil comments, and its potential difference between L1 and L2, in online settings (Twitter) where both proponents and opponents of a particular view can express themselves in a civil or uncivil manner.

Before describing the details of our studies, we revise pertinent research on the effects of online incivility and emotional reactions in an L2.

\section{Online Incivility}

Even if it is an action we carry out on a daily basis, searching for information on the Internet presents a number of challenges: the variety of information forces readers to locate and select sources; banners, links, and other documents may distract or divert from the searching task; information is less filtered for quality and accuracy than in print (see Salmerón, Kammerer, \& Delgado, 2018, for a review), and additional 
information may be provided by other users' comments, for example, on social media, forums, blogs or in the comment section of news sites (Baek, Wojcieszak, \& Delli Carpini, 2012; Kleinke, 2008; Muddiman \& Stroud, 2017; Sampietro \& Valera-Ordaz, 2015). As comments may be in favor of or against the issue presented, Internet users have easy access to different and potentially contradictory opinions on a specific topic. Moreover, the perception of the issue under debate can also vary according to the civility or incivility of the accompanying comments. Incivility, ${ }^{1}$ which includes various phenomena, such as, mockery, name-calling, exaggeration and personal attacks (Gervais, 2015; 2017; Sifianou, 2019), is frequently found in online discussions (Coe, Kenski, \& Rains, 2014; Lee \& Pang, 2014; Papacharissi, 2004). While incivility is not negative per se and should not be completely banned (Chen, Muddiman, Wilner, Pariser, \& Stroud, 2019), there is evidence that uncivil discussions can lead to negative outcomes. Nasty and attacking remarks have been linked to distrust in politics (Mutz \& Reeves, 2005), negative impressions of brands and news (Anderson et al., 2018; Prochazka, Weber, \& Schweiger, 2018; Tenenboim, Chen, \& Shuning, 2019), negative views of online discussions (Gervais, 2015; Hwang et al., 2014; Ng \& Detenber, 2006), feelings of anger, aggressiveness, and aversion (Gervais, 2015; 2017), and polarization of opinions, especially among individuals with strong previous beliefs (Anderson et al., 2014). By contrast, civil comments are usually considered more rational (Popan et al., 2019) and persuasive (Chen $\& \mathrm{Ng}, 2016)$.

\footnotetext{
${ }^{1}$ The concepts of incivility and impoliteness are hard to define and measure (Chen et al., 2019; O'Sullivan \& Flanagin, 2003; Papacharissi, 2004; Sifianou, 2019). As this paper addresses this issue in relation to online deliberation rather than from an interpersonal perspective, the term 'incivility' will be preferred. For a recent discussion of the concept of (in)civility versus (im)politeness cf. Sifianou (2019).
} 
In one well-cited study, Anderson et al. (2014) gave a representative sample of US population an online newspaper article on the pros and cons of a largely unfamiliar topic, nanotechnology, followed by a civil or uncivil comment. These authors measured polarization taking 'risk perception' as the dependent variable of their study, as controversies about modern technologies frequently focus on risk (Sjöberg, 2004). They found that incivility drove a polarization of risk perception of nanotechnology, especially among individuals who did not support nanotechnology or among highly religious people. According to the authors, this means that when faced with incensed comments online, people rely more on previous beliefs or heuristics (Anderson et al., 2014). In the present paper, we seek to explore if this effect is also true for people reading in an L2. As it will be shown below, psycholinguistic research on bilingualism, in fact, has found that affective processing in an L2 is less automatic and triggers lower affective reactions (see Pavlenko, 2012 for a comprehensive review), which has been linked with a reduction of framing biases and more rational decision-making (Costa, Foucart, Arnon, et al., 2014; Hadjichristidis et al., 2015; Keysar et al., 2012).

\section{Emotional Distance in an $\mathbf{L 2}$}

Research on bilingualism has acknowledged the complexity of the relationship between linguistic experience and emotional processing (Freeman, Shook, \& Marian, 2016; Pavlenko, 2008, 2012). Studies conducted with different methods, such as interviews, questionnaires, memories, experimental tasks, psychophysiological approaches, and neuroimaging demonstrate that bilinguals show stronger emotional responses in their native language (Caldwell-Harris, 2014; Pavlenko, 2005; 2012). The reduced emotionality in an L2 is especially evident in unbalanced bilinguals, e.g. people who display greater ease in one of the languages, as, for example, L2 learners (Opitz \& Degner, 2012). For example, saying 'I love you' is perceived differently when proffered 
in a foreign language (Dewaele, 2010), because of the stronger emotional experience in the L1 (Pavlenko, 2005). This is also true for negative emotions. Bilingual speakers tend to change from L2 to L1 in conversation after showing a negative facial emotion (Williams, Srinivasan, Liu, Lee, \& Zhou, 2019), or when recalling harmful memories (Ladegaard, 2018). Moreover, bilingual speakers usually shout in their L1 when in anger (Pavlenko, 2005), and perceive swear words strongly in the L1 than in the L2 (Dewaele, 2004; Pavlenko, 2008). In the same vein, it has been shown that ChineseEnglish bilinguals spoke longer about embarrassing topics in the L2 (Bond \& Lai, 1986), given the increased emotional distance with a later-acquired language (Bond \& Lai, 1986; Caldwell-Harris, 2014; Pavlenko, 2008).

Experimental studies have shown that the reduced emotional response in an L2 allows people to be less affected by decision biases when using an L2 than in their native language, as they rely on more systematic processes in decision-making (Keysar et al., 2012). Keysar et al. (2012) replicated the Asian disease problem ${ }^{2}$ with bilinguals, specifically observing the influence of L2 on the framing effect, i.e. the fact that the way a given problem is presented, such as negatively or positively, influences participants' reasoning about gains or losses. Results replicated the framing effect in a sample of monolingual participants, but this effect disappeared when bilinguals read the problem in an L2. These findings were consistent across different decision-making situations, such as moral dilemmas, financial decisions, and risk-taking behaviors (Costa, Foucart,

\footnotetext{
${ }^{2}$ The Asian disease problem is a famous experiment designed by Nobel laureate Daniel Kahneman and his colleague Amos Tversky (Tversky \& Kahneman, 1981) in which they asked participants to choose among four options the best program to combat the outbreak of an unusual Asian disease that is expected to kill 600 people. Options were equivalent, but simply framed differently. Results robustly showed that subjects are risk-averse for gains and risk-seeking for losses.
} 
Arnon, et al., 2014; Costa, Foucart, Hayakawa, et al., 2014; Geipel, Hadjichristidis, \& Surian, 2015a; Hayakawa, Costa, Foucart, \& Keysar, 2016; Keysar et al., 2012). The overall interpretation is that the framing effect is diminished when subjects took decision-making tests with an emotional basis in an L2 (Geipel et al., 2015a; Keysar et al., 2012).

This paper explores the effects of a specific type of affective information in a second language, verbal incivility, by replicating Anderson's et al. (2014) study on the effects of nasty comments on risk perception of emerging technologies adding a L2 condition (Study 1) and further testing the findings in a different scenario, a debate in Twitter (Study 2). Based on the facts that civil comments are usually considered more rational and persuasive in an L1 (Chen \& Ng, 2016; Popan et al., 2019), and that emotional terms have a weaker effect in an L2 (Pavlenko, 2008, 2012), we expect that civility of online comments will have different influences on risk perception of scientific topics contingent on the language in which they are written. Finally, given that we used only monolingual discussions (either in participants' L1 or in the L2), where participants discussed using the same language, we did not expect that the status of language (i.e. prestige of English) could be used as a heuristic cue to evaluate the quality of the arguments (Rösner et al., 2014; Tan et al., 2008). Specifically, the following hypotheses will be tested:

Hypothesis 1. While reading in an L1, bilingual participants will align their risk perception to the view supported by civil comments to a higher extent than the view supported by uncivil ones.

Hypothesis 2. While reading in an L2, bilingual participants will not change their risk perception, regardless of the civility of online comments. 


\section{Study 1}

\section{Method}

Participants. Participants were 77 bilingual undergraduate and graduate students from a large university in Spain ( $M$ age $=21.26$ years, $S D=4.64,63$ women $)$, from different disciplines such as Translation Studies, Psychology, and Education. Participants volunteered for class credit. They were native speakers of Spanish, and they acquired the second language (i.e. English) through formal education during adolescence and adulthood. Specifically, their level of English corresponded to at least upper intermediate level (level B2 of the Common European Framework of Reference for Languages ${ }^{3}$ ), as indicated by their scores on official tests. In addition, scores from a research-oriented short online test of English proficiency (Lemhöfer \& Broersma, 2012), corroborated their upper intermediate level. According to the authors, scores between $60-80 \%$ correspond to a CEFR B2 level, and participants scored on average $70.5(S D=6.2)$. In the main analyses, we used data from the 70 participants that completed all the tasks. Participants provided an informed consent form prior to participation, and all the data was anonymized to ensure privacy.

\section{Materials.}

Texts. Participants read two newspaper online articles about the risks and benefits of nanotechnology and biofuels, adapted from the materials used by KnoblochWesterwick, Johnson, Silver, and Westerwick (2015). These topics were selected as they

\footnotetext{
${ }^{3}$ The Common European Framework of Reference for Languages: Learning, Teaching, Assessment (CEFR) is a guideline used to elaborate language syllabuses, curricula, to grade an individual's language proficiency, and to provide a basis for recognizing language qualifications across Europe (Council of Europe, 2019). It includes six levels (A1, A2, B1, B2, C1, and C2). B2 corresponds to an upper intermediate level.
} 
were rather unfamiliar to students, thus avoiding biases caused by strong previous beliefs or personal involvement (Anderson et al., 2014; Tan et al., 2008). The articles presented the conflicts in a balanced way, providing one argument about the risks and another argument about the benefits of nanotechnology/biofuels (Table 1).

\section{[TABLE 1]}

The articles simulated the layout of an online newspaper, with the BBC logotype on the top of the page and a frame that imitated a comment section at the bottom of the page. As the original texts were written in English, materials were translated from English into Spanish by one of the authors; materials were reviewed by native speakers of both languages for accuracy and authenticity. The English version of the text on nanotechnology was 411 words long (457 in Spanish), and the English version of text on biofuels was 334 words long (409 in Spanish).

Online comments. Texts were followed by an anonymous comment between 56 and 72 words in length $(M=65.38, S D=6.91)$ written in a civil or uncivil manner, which added an additional claim about either risks or benefits of the issue discussed in the text. The additional argument was the same for each topic, but it was preceded by a polite or impolite header. The polite headers were: 'In my opinion, these arguments are quite incorrect. I read myself a report that didn’t present such good data' for biofuels, and: 'Honestly, I don't agree with the author of the article, as they seem to overlook some clear advantages of nanotechnology' for the other topic. The impolite headers were: 'This is a completely stupid article!! The author is an ignorant person, as I have read myself a report that didn't present such good data' for the biofuels news report, and: 'The author is an idiot. Please, investigate a bit on the advantages of nanotechnology before writing this shit!' for the nanotechnology news report. 


\section{Questionnaires.}

Familiarity. Familiarity was assessed by means of the question: 'How much have you heard, read, or seen about nanotechnology (or biofuels)'? in a scale from $1=$ 'Nothing at all' and $10=$ 'Very much' (Anderson et al., 2014).

Support. Initial support towards the topic was assessed by asking the questions: 'Overall, I support the use of nanotechnology (or biofuels),' where 1 = 'Do not agree at all' and $10=$ 'Agree very much' (Anderson et al., 2014).

Risk perception. We assessed participants' risk perception on each topic using the item developed by Anderson et al. (2014). Specifically, the item read: 'On the issue of nanotechnology (or biofuels), do you think the benefits outweigh the risks, the risks outweigh the benefits, or the risks and benefits are about the same'? The scale ranged from $1=$ 'Benefits far outweigh the risks' to $5=$ 'Risks far outweigh the benefits.'

Perceived civility of the online comment. Participants rated the civility of the comment, by responding to the question: 'How would you rate the civility of the author of the comment on the article on nanotechnology (or biofuels)'? The scale ranged from $1=$ 'Very impolite' to $5=$ 'Very polite.'

Summary task. Participants wrote a short summary of the article in Spanish (participants' native language), even if they read one of the texts in English. The number of textual arguments in the summaries (sum of arguments drawn from the text and from the comment) was coded. For example, the following summary included a negative argument from the text (food prices rise due to the production of biofuels) and an additional idea from the comment (ethanol produces more pollution per unit of energy):

I enjoyed reading about biofuels because I didn't know much about it. I think it's a big problem that farmers are more interested in the production of biofuels than food and that 
this will lead to a rise in the price of the latter. Regarding the benefits or disadvantages for the environment, I thought that biofuel was less polluting than gasoline, as it comes from petrol, but ethanol produces more pollution per unit of energy burned.

To ensure the reliability of the coding system, $10 \%$ of the summaries were rated by the two authors, resulting in a high agreement (86.7\%). Inconsistencies were agreed upon discussion, and the first author coded the remaining summaries.

\section{Design.}

The experiment was an incomplete 2 civil (civil vs. uncivil) x 2 language (L1 vs. L2) mixed design. All students read two texts, one in each language. For half of the students, the text read in their L1 included a civil comment, and the L2 text an uncivil one. For the other half, the L1 text included an uncivil comment, and the L2 text a civil one. Across participants, text topics were counterbalanced across languages and civility. The main dependent variable was attitude change towards the view reported in the comment. To calculate such index, we subtracted the risk perception scores (inversed and centered) and the initial support centered scores, and adjusted the sign to the view expressed in the comment. A change towards a more positive attitude was left as positive if the comment discussed a benefit, but it was changed to negative if the comment included a risk. From these scores were created three groups: a score higher than 0 indicated that participants' risk perception changed towards the view expressed in the comment, a score lower than 0 that their perception changed in the opposite direction of the view expressed in the comment, and a 0 indicated that participants did not change their attitude towards the topic.

\section{Procedure.}


The study took place in computer labs, in groups of approximately 15 participants, in 60 minutes' sessions. Participants were randomly assigned to one of the two sequences of the study: half of them read a text with a civil comment both in the L1, and a text with an uncivil comment in the L2, while the other half read a text with an uncivil comment in the L1, and a text with a civil comment in the L2. Upon arrival, participants completed the pre-test measures. Then, they read the texts at their own pace. Afterwards, they completed the post-test measures and wrote a summary for each text. They were allowed to re-read the text before writing the summary. Finally, participants' English level was assessed by means of a brief standardized online test (Lemhöfer \& Broersma, 2012).

\section{Results}

First, we checked participants' level of familiarity and support to the topic used. Overall, participants indicated that they were not much familiar with the topics discussed $\left(M_{\text {nanotechnology }}=3.2, S D=1.7, M_{\text {biofuels }}=4.3, S D=1.9\right)$, and they tended to have neutral or slightly positive attitudes towards them $\left(M_{\text {nanotechnology }}=5.8, S D=1.8\right.$, $\left.M_{\text {biofuels }}=7.2, S D=1.8\right)$. Next, to ensure that the manipulation was effective, we analyzed students' perception of the civility of the comments for each language. As expected, for the $\mathrm{L} 1$ texts participants rated the civil $(M=3.6, S D=1.2)$ as more polite than the uncivil $(M=1.6, S D=1.0)$ comment, $t(68)=7.0, p<.001, d=1.7$. More critical, for the L2 texts participants rated as more polite the civil $(M=3.7, S D=1.0)$ than the uncivil $(M=1.8, S D=1.2)$ comment, $t(68)=7.3, p<.001, d=1.9$. Next, to ensure that participants understood the text in both languages, we analyzed the quality of the summaries by language. Participants included a similar number of correct ideas included in the summaries for the L2 texts $(M=2.1, S D=0.4)$ as for the L1 texts $(M=$ 2.0, $S D=0.5), t(69)=1.2, p=.18, d=0.1)$. 
In sum, the results indicated that participants identified uncivil online comments as impolite and understood the texts to a similar degree in the L1 and in the L2. Next, we tested the assumptions that comments' civility will affect participants' attitude towards the topic, contingent on the language of the text.

\section{Comment civility and attitude change.}

We used Chi-square tests to analyze the effect of text language (L1 vs. L2) and comment civility (civil vs. uncivil) on participants' attitude change towards the view reported in the comment. Across subgroups, descriptive data revealed that the majority of participants did not change their attitude from pre to post-test (percentages ranged from 39.5 to 60.5 , see Table 2). Comparing groups across language, when participants read L1 texts, analyses indicated that comment civility significantly affected participants' attitude change, $\chi^{2}(2)=10.21, p<.01$, Cramer's $V=.39$. According to Cohen's (1988) effect size benchmarks, this is a large effect. But when participants read L2 texts, comment civility did not affect participants' attitude change, $\chi^{2}(2)=2.12, p$ $=.34$, Cramer's $V=.18$.

\section{[TABLE 2]}

To interpret the effect, we conducted follow up Wilcoxon Rank tests comparing the number of participants who changed their attitude towards the view expressed in the comments, against the others (i.e. no change or change against the comment).

Supporting hypotheses 1 and 2, results showed that participants reading in an L1 changed their attitude more often towards the view expressed by civil, rather than uncivil, comments, $Z=2.8, p<.01, r=.33$ (hypothesis 1 ), while those reading in the L2 did not modify their attitude contingent on the civility of the comments, $Z=1.3, p=.17$, $r=.15$ (hypothesis 2). 
Descriptive data suggested that the effect on comment civility in the L1 is largely due to the fact that participants tend to subscribe to a lower extent the uncivil comment in the L1 (approximately $41 \%$ less than in the L2), rather than subscribing to a higher extent the civil comment (approximately 5\% more than in the L2). Of note is that the change on attitude towards the view expressed in civil comments in L1 is a medium effect, according to Cohen's benchmarks (1988).

\section{Discussion}

Overall, the results of Study 1 partially replicate Anderson's et al. (2014) findings in a sample of bilingual participants. Results show that, among bilinguals with no strong previous beliefs, the level of civility of online comments written in an L1 influenced participants' attitude change. Specifically, while civil comments in an L1 triggered a change in attitude more often toward the view expressed in the comment, uncivil comments in an L1 had a lower 'attraction' on attitudes (Chen \& Ng, 2016; Popan et al., 2019).

In line with Anderson's et al. (2014) study, perceptions toward scientific issues in an L1 are shaped not only by the arguments exposed in the text but also by other people's viewpoints, as expressed in the comment section. User-generated comments are thus an important factor affecting persuasion, as also observed by Walther et al. (2018). In addition, the results extend the 'nasty effect' to online news and comments in an L2, demonstrating that the civility of the comment did not affect attitude change in the L2. In support of hypothesis 2, this study corroborates in a natural setting that people who read scientific online information in an L2 are not impacted by the emotionality of the uncivil comments accompanying the text. The scenario used in study 1 presented an unbalanced communication scenario, as the journalist who formally presented the news report could not counterargue the commentator. In 
addition, participants could refer to the ideas expressed in the text (balanced) to judge the comments' relevance. A second experiment was designed to further study this effect, but in a different and more interactive online scenario, a debate on Twitter, in which the specific weight of civility and incivility were tested. In fact, newspaper articles in Study 1 included a balanced number of arguments in favor or against nanotechnologies and biofuels and only one comment in either direction. Even if people frequently interact with users with similar views on social media (Barberá, Jost, Nagler, Tucker, \& Bonneau, 2015; Baviera, Sampietro, \& García-U11, 2019; Sunstein, 2017), it is possible to find different arguments for or against a topic (Brundidge, 2010; Holt, 2004; Popan et al., 2019), hence a discussion among users with different opinions and civility could be generated e.g. around scientific issues (Knobloch-Westerwick et al., 2015). Thus, study 2 was designed to analyze the effect of incivility in a Twitter debate on scientific issues in an L1 and L2.

\section{Study 2}

\section{Method}

Participants. Participants were 22 bilingual undergraduate and graduate students from a large university in Spain $(M$ age $=31.6$ years, $S D=9.8 ; 18$ women $)$ who came from different degrees, including Psychology and Education. Participants volunteered following an open call to students across the campus. They were all native speakers of Spanish. As in Experiment 1, they had learnt English at school, they had passed an official English proficiency test corresponding to upper intermediate level (i.e. B2 of the CEFR or higher), and their scores from a short online English test (Lemhöfer \& Broersma, 2012) corroborated this point $(M=74.7, S D=9.4$ corresponding to an upper-intermediate level). Participants provided informed consent 
prior to participation, and all the data was anonymized to ensure privacy. None of them had participated in Study 1.

Materials. The experiment recreated four Twitter debates around four socioscientific issues: biofuels, nanotechnology, fracking, and genetically modified organisms (GMO). Tweets were adapted from the materials used by KnoblochWesterwick et al. (2015). These topics were selected as issues related to emerging technologies are usually unfamiliar (Anderson et al., 2014).

Each discussion included 25 tweets of 3 different types: civil (10), uncivil (10) or neutral (5). Specifically, each tweet presented a brief argument in favor of or against the topic under debate, preceded by a short header. This header was either polite or impolite. Concretely, impolite headers presented either insults or rude words, and were directed to third persons (e.g. 'What a bunch of idiots'!). Polite headers were written in the first person plural and in an educated way (e.g. 'We should learn more about that'). Neutral tweets were added as distractors. These tweets did not present arguments related to the topic, but only jokes, displays of interest, or claims about the need to deal with these or other topics (e.g. 'We can fight for or against nanotechnology, but on one thing we will all agree: it shows that size does matter').

We created two language versions of the tweets, by translating arguments into Spanish from the original English materials (Knobloch-Westerwick et al., 2015). Tweets were reviewed and slightly modified by native speakers of both languages, to ensure that they could be perceived as a regular tweet in each language. Tweets written in Spanish ranged from 128 to 206 characters $(M=171.33, S D=18.49)$, while those written in English were from 111 to 199 characters in length $(M=156.19, S D=21.97)$. 
Materials were presented in an interface that simulated Twitter: alongside each tweet, there was a squared picture of the face of the fictitious author of the tweet (half male and half female), and on top, the name and last name of the author were included. Names corresponded to common Spanish first and last names; we did not mix Spanish and English names to avoid the potential effect of the perceived origin of the author or in-group identification (but see Walther et al., 2018). The interface showed the logo of the platform, but metrics on engagement (likes, comments, retweets), and hashtags were not included.

We created two types of discussions by manipulating the percentage of civil comments favoring a particular view (i.e. pro or against the topic) (see Table 3). All discussions included the same number of tweets in favor (pro-topic) and against the topic (against-topic) being discussed, as well as neutral tweets. On the one hand, in civil pro-topic discussions $80 \%$ of the tweets including an argument in favor of the topic discussed were civil, and only $20 \%$ uncivil. Conversely, in these discussions $20 \%$ of the tweets against-topic were civil, and $80 \%$ uncivil. On the other hand, in civil againsttopic discussions, $80 \%$ of the tweets including an argument against the topic discussed were civil, and only $20 \%$ uncivil. Conversely, in this type of discussions $20 \%$ of the tweets in favor of the topic were civil, and $80 \%$ uncivil. Topics were counterbalanced across languages and civility of the discussion.

\section{[TABLE 3]}

Tweets and discussions were carefully created to control for potential confusion of argument, civility, and language. Across participants, a tweet with an identical argument was preceded $50 \%$ of the times by a civil heading, and $50 \%$ of the times by an uncivil one. Similarly, the same tweet appeared across participants $50 \%$ of the times in the L1 and 50\% in the L2. Order of appearance of tweets was randomized across 
participants. Topic assignment to condition (discussion type and language) was also randomized.

All participants followed two civil pro-topic discussions (one in an L1 and one in an L2 -see first two rows in Table 3), and two civil against-topic discussions (one in an L1 and one in an L2 -see last two rows in Table 3). Each discussion was presented separately, using an ad-hoc program written in Visual Basic for this project. Specifically, participants read one tweet at a time and pressed the space bar to indicate that they had finished reading it. To ensure that they processed the information from the tweets, after reading each tweet, participants indicated its perceived relevance for the debate in a 1 to 9 scale. After the response, the program automatically presented a new tweet.

Questionnaires. We used the same questionnaires as Study 1 to assess familiarity, initial support and post-test risk perception, adapted for each of the four topics used. Attitude change was computed in the same way as in Study 1, by subtracting participants risk perception (inversed scores and centered) to pre-test support (centered).

Design. The experiment was a complete 2 (civility: civil pro-topic vs. uncivil pro-topic) x 2 (language: L1 vs. L2) within-participant design.

Procedure. Participants worked individually in a quiet room at the university. The whole session lasted approximately 30 minutes. First, participants completed the pre-test measures. Afterwards, they were introduced to follow the debates on Twitter. In order to familiarize participants with this rating task and the computer program, the four discussions were preceded by an additional training debate written in an L1, composed by 10 tweets in favor or against the use of school uniforms. After we ensured they had understood the task, they started to read the four debates about nanotechnology, 
biofuels, fracking, and GMOs, rating each comment for relevance. A 1-minute pause was enforced after finishing each discussion, to ensure that participants could elaborate on the topic they had just read. Finally, they completed the post-test measures. After completing all the tasks, they took a short English test (Lemhöfer \& Broersma, 2012).

\section{Results}

As was the case in Study 1, familiarity with the topics tended to be low $\left(M_{\text {biofuels }}=4.64\right.$, $S D=1.99 ; M_{\text {nanotechnology }}=4.45, S D=2.15 ; M_{\text {fracking }}=3.32, S D=2.78 ;$ and $M_{G M O s}=$ $6.32, S D=1.91)$. Similarly, participants tended to show a slightly positive initial support towards biofuels and nanotechnology $\left(M_{\text {biofuels }}=7.27, S D=1.96 ; M_{\text {nanotechnology }}=6.91\right.$, $S D=1.66)$, while a slightly negative initial support for fracking and GMO ( $M_{\text {fracking }}$ $=3.82, S D=1.76$; and $\left.M_{G M O S}=4.09, S D=2.41\right)$.

\section{Civility of discussion and attitude change}

We used Chi-square tests to analyze the effect of text language (L1 vs. L2) and discussion view (civil pro-topic vs. uncivil pro-topic) on participants' attitude. When participants read Twitter discussions in the L2, the civility of the pro-topic supporters did not affect participants' attitude change, $\chi^{2}(2)=0.59, p=.75$, Cramer's $V=.17$. But when participants read the discussion in their L1, data revealed that the civility of the pro-topic supporters significantly affected participants' attitude change, $\chi^{2}(2)=8.0, p$ $=.01$, Cramer's $V=.63$ (i.e. large effect, see Cohen (1998)). We conducted follow up Wilcoxon Rank tests to interpret the pattern of effects. Specifically, we compared the number of participants who changed their attitude towards the pro-topic view, against the others (i.e. no change or change against pro-topic view). Supporting our hypotheses, results showed that when participants read in the L1, they changed their attitude more often towards the pro-topic view when the majority of the Twitter pro-topic discussants 
expressed their view in a civil rather than in uncivil manner, $Z=2.7, p<.01, r=.58$ (i.e. large effect, see Cohen (1998)). When reading in the L2, participants did not change their attitude contingent on the civility of the posts, $Z=0.3, p=.76, r=.06$.

As shown in Table 4, descriptive data suggested that the effect of discussion civility in the L1 is due both to the fact that participants tend to subscribe to a higher extent the pro-topic view when their supporters expressed themselves mostly in a civil manner (approximately 14\% more than in the L2), and tend to go away from pro-topic views when their supporters discussed in an uncivil manner (approximately $9 \%$ less than in the L2). Of note is that the effect of discussion civility in the L1 is a large effect, which speaks about its relevance.

\section{[TABLE 4]}

\section{Discussion}

Unlike the previous scenario described in Study 1 (a balanced news report followed by an additional anonymous online comment), in these Twitter debates there was a potential discussion between educated and rude users, and readers did not have a balanced text to refer to when judging the relevance of the comments. Findings of Study 2 were consistent with those of Study 1 and with Hypothesis 2 in showing that when reading a debate on emerging technologies in an L2, the civility or incivility of the tweets did not affect risk perception. On the contrary, as in Study 1, in debates written in participants' mother tongue, the civility of the topic significantly affected post-test risk perception measures (Anderson et al., 2014). This means that, independently from the argument, civil tweets in the L1 affect more attitude change, while uncivil tweets written in the L1 are less influential (Chen \& Ng, 2016; Popan et al., 2019). Thus, the results of this study are also consistent with Hypothesis 1. 


\section{General Discussion}

The present study tested whether uncivil online comments about emerging technologies written in a foreign language have also a polarizing effect on attitudes of bilingual people, as shown in a study conducted in English on a representative sample of US population (Anderson et al., 2014). Drawing on literature on emotional processing in an L2 (Costa, Foucart, Arnon, et al., 2014; Keysar et al., 2012), we expected that uncivil comments written in the L2 would have a less relevant role in polarizing attitudes about these socioscientific issues. Overall, the findings support with medium and large effects the hypotheses that the civility of the comments written in the L1 significantly affect risk perception in populations without extreme previous attitudes on emerging technologies (Anderson et al., 2014), while no effect is observed when users read comments in the L2.

Specifically, in their mother tongues, participants gave more support to views conveyed by educated messages, and less to opinions supported by rude messages. This is likely because users of profanity generate less favorable impressions, thus individuals using uncivil expressions may be considered less trustworthy (DeFrank \& Kahlbaugh, 2019) or less rational (Popan et al., 2019). But in a foreign language, participants did not change their support to a particular view regardless of the civility of the online comments. As the scenarios used in our studies included a similar amount of relevant arguments pro and against the topics, a rational response was not to change the original perception of the controversy. We hypothesized that in the L2 participants experienced lower emotional reactions to civil and uncivil online comments (see Pavlenko, 2008, 2012), which allowed for a more rational approach to interpreting the socio-scientific controversy.

Originally, the 'nasty effect' was found in a study using online news commentaries with English-speaking participants (Anderson et al., 2014). Of note is that we not only replicated the effect in a language other than English with bilingual participants (i.e. 
Spanish was our participants' mother tongue), but also in a totally different online scenario (Twitter). Specifically, we replicated the effects of online civility and language (L1 or L2) in two different online scenarios, in online news comment sections and on a social media platform (Twitter). In the scenario of online news deliberation, uncivil comments were addressed against a formal account of the controversy, which was written by a journalist. This situation could have increased participants' perception of the communication exchange as unfair, thus penalizing the fact that the news reporter could not counterargue the commentator. One may argue that such an unfair situation, and not the civility of the comments, could partially explain participants' negative reaction against uncivil online comments. In a second study using Twitter as the scenario, we ruled out this possibility, as both proponents and opponents of particular views on socio-scientific controversies could speak their voice to defend their position in a more or less polite manner. The fact that both studies converge on similar results suggests that comment civility, and not the interactivity of the online scenarios, is responsible for participants' attitude change when reading in their $\mathrm{L} 1$.

Our studies used single-language discussions, and therefore limited participants' consideration of the prestige of English as heuristic to evaluate the comments (Rösner et al., 2014; Tan et al., 2008). In multilingual online discussions, civility of comments, prestige of language and mother tongue could interact in complex ways. For example, the positive influence of a civil comment in the L1 found in our studies could be reduced if that comment addressed a text in an L2 with a higher perceived status. Future studies should address this issue.

This study also comes with limitations. In both experiments, participants selfassessed their knowledge and support for emerging technologies, but like in Anderson's et al. study (2014), their actual knowledge was not tested. High background knowledge 
on a controversy could allow participants to move beyond the civility of the comments and to focus on the conceptual discussion and the reliability of the sources (Bråten, Strømsø, \& Salmerón, 2011). In addition, our participants did not hold strong attitudes towards the topics discussed in the studies, which could have limited the emotional reactions elicited by the text arguments (List \& Alexander, 2017). In the future, more controversial topics could be chosen, such as national politics, feminism, or politicized socio-scientific issues (e.g. vaccines, abortion, climate crisis, etc.), where participants' previous attitudes and emotions may be stronger (Kleinke, 2008; Sampietro \& ValeraOrdaz, 2015). For example, on the issue of abortion, Chen and $\mathrm{Ng}$ (2016) found that people consider online civil comments as more persuasive, regardless of the view expressed, while Popan et al. (2019) found that in political discussions, civil comments were frequently rated as more rational, regardless of strength of the argument provided. Future studies could test if these findings are also true for comments written in an L2 or if the argument is more influential in a second language, as could be expected from our results.

Another limitation concerns our sample of bilingual participants, as most of them acquired the second language (i.e. English) through formal education during adolescence and adulthood. Although English as a second language is quite popular in Spain, participants' mother tongue (i.e. Spanish) remains predominant in society. Results may not be generalized to people with different linguistic trajectories, such as those who live in bilingual countries or regions, or immigrants, because early age of acquisition, high proficiency, language learning via immersion, and high-usage frequency may increase the emotional resonance of a second language (Caldwell-Harris, 2014). Future research should replicate our experiments with people with different L2 levels or with different 
languages, in order to test differences in attitude change depending on the proficiency in the second language.

Despite these limitations, we believe that our study makes an important contribution to understand how online communication is affected by reading in an L2, by assessing the effects of incivility in analyzing controversial arguments in a foreign language.

\section{Acknowledgments}

We thank Christian Tarchi for his comments on an earlier version of the manuscript, and Kate Ziegelstein for her assistance to the project.

\section{References}

Anderson, A. A., Brossard, D., Scheufele, D. A., Xenos, M. A., \& Ladwig, P. (2014). The 'nasty effect:' Online incivility and risk perceptions of emerging technologies. Journal of Computer-Mediated Communication, 19(3), 373-387. doi: $10.1111 /$ jcc4.12009

Anderson, A. A., Yeo, S. K., Brossard, D., Scheufele, D. A., \& Xenos, M. A. (2018). Toxic talk: How online incivility can undermine perceptions of media. International Journal of Public Opinion Research, 18(1), 156-168. doi: 10.1093/ijpor/edw022

Baek, Y. M., Wojcieszak, M., \& Delli Carpini, M. X. (2012). Online versus face-to-face deliberation: Who? Why? What? With what effects? New Media \& Society, 14(3), 363-383. doi: 10.1177/1461444811413191

Barberá, P., Jost, J. T., Nagler, J., Tucker, J. A., \& Bonneau, R. (2015). Tweeting from left to right: Is online political communication more than an echo chamber? Psychological Science, 26(10), 1531-1542. doi: 10.1177/0956797615594620

Baviera, T., Sampietro, A., \& García-U11, F. J. (2019). Political conversations on Twitter 
in a disruptive scenario: The role of 'party evangelists' during the 2015 Spanish general elections. The Communication Review, 22(2), 117-138. doi: $10.1080 / 10714421.2019 .1599642$

Benkler, Y. (2006). The wealth of networks: How social production transforms markets and freedom. New Haven and London: Yale University Press.

Bond, M. H., \& Lai, T. (1986). Embarrassment and code-switching into a second language. The Journal of Social Psychology, 126(2), 179-186.

Bråten, I., Strømsø, H. I., \& Salmerón, L. (2011). Trust and mistrust when students read multiple information sources about climate change. Learning and Instruction, 21(2), 180-192. doi: 10.1016/j.learninstruc.2010.02.002

Brundidge, J. (2010). Encountering 'difference' in the contemporary public sphere: The contribution of the internet to the heterogeneity of political discussion networks. Journal of Communication, 60(4), 680-700. doi: 10.1111/j.1460-2466.2010.01509.x

Caldwell-Harris, C. (2014). Emotionality differences between a native and foreign language: Theoretical implications. Frontiers in Psychology, 5(SEP), 1-4. doi: 10.3389/fpsyg.2014.01055

Chen, G.M., Muddiman, A., Wilner, T., Pariser, E., \& Stroud, N. J. (2019). We should not get rid of incivility online. Social Media+Society, 5(3). doi: $10.1177 / 2056305119862641$

Chen, G. M., \& Ng, Y. M. M. (2016). Third-person perception of online comments: Civil ones persuade you more than me. Computers in Human Behavior, 55, 736742. doi: 10.1016/j.chb.2015.10.014

Coe, K., Kenski, K., \& Rains, S. A. (2014). Online and uncivil? Patterns and determinants 
of incivility in newspaper website comments. Journal of Communication, 64(4), 658-679. doi: 10.1111/jcom.12104

Cohen, J. (1988). Statistical power and analysis for the behavioral sciences. Hisdale, NJ: Lawrence Erlbaum Associates.

Costa, A., Foucart, A., Arnon, I., Aparici, M., \& Apesteguia, J. (2014). 'Piensa' twice: On the foreign language effect in decision making. Cognition, 130(2), 236-254. doi: 10.1016/j.cognition.2013.11.010

Costa, A., Foucart, A., Hayakawa, S., Aparici, M., Apesteguia, J., Heafner, J., \& Keysar, B. (2014). Your morals depend on language. PLoS ONE, 9(4), e94842. doi: 10.1371/journal.pone.0094842

Council of Europe. (2019). Common European Framework of Reference for Languages: Learning, teaching, assessment (CEFR). Retrieved August 1, 2019, from https://www.coe.int/en/web/common-european-framework-reference-languages

Dahlgren, P. (2005). The Internet, public spheres, and political communication: Dispersion and deliberation. Political Communication, 22(2), 147-162. doi: $10.1080 / 10584600590933160$

DeFrank, M., \& Kahlbaugh, P. (2019). Language choice matters: When profanity affects how people are judged. Journal of Language and Social Psychology, 38(1), 126-141. doi: $10.1177 / 0261927 X 18758143$

Dewaele, J.-M. (2004). The emotional force of swearwords and taboo words in the speech of multilinguals. Journal of Multilingual and Multicultural Development, 25(2-3), 204-222. doi: 10.1080/01434630408666529

Dewaele, J.-M. (2010). Emotions in multiple languages. London: Palgrave Macmillan. 
doi: $10.1057 / 9780230289505$

Freeman, M. R., Shook, A., \& Marian, V. (2016). Cognitive and emotional effects of bilingualism in adulthood. In E. Nicoladis \& S. Montanari (Eds.), Bilingualism Across the Lifespan. Factors Moderating Language Proficiency (pp. 285-304). Berlin: De Gruyter/Mouton.

Geipel, J., Hadjichristidis, C., \& Surian, L. (2015a). How foreign language shapes moral judgment. Journal of Experimental Social Psychology, 59(February), 8-17. doi: 10.1016/j.jesp.2015.02.001

Geipel, J., Hadjichristidis, C., \& Surian, L. (2015b). The foreign language effect on moral judgment: The role of emotions and norms. PLoS ONE, 10(7), e0131529. doi: 10.1371/journal.pone.0131529

Gervais, B. T. (2015). Incivility online: Affective and behavioral reactions to uncivil political posts in a web-based experiment. Journal of Information Technology \& Politics, 12(2), 167-185. doi: 10.1080/19331681.2014.997416

Gervais, B. T. (2017). More than mimicry? The role of anger in uncivil reactions to elite political incivility. International Journal of Public Opinion Research, 29(3). doi: 10.1093/ijpor/edw010

Grosjean, F. (2010). Bilingual: Life and reality. Cambridge: Harvard University Press.

Hadjichristidis, C., Geipel, J., \& Savadori, L. (2015). The effect of foreign language in judgments of risk and benefit: The role of affect. Journal of Experimental Psychology: Applied. doi: 10.1037/xap0000044

Hayakawa, S., Costa, A., Foucart, A., \& Keysar, B. (2016). Using a foreign language changes our choices. Trends in Cognitive Sciences, 20(11), 791-793 doi: 
10.1016/j.tics.2016.08.004

Holt, R. (2004). Dialogue on the Internet: Language, civic identity, and computermediated communication. Westport, CT: Praeger.

Hwang, H., Kim, Y., \& Huh, C. U. (2014). Seeing is believing: Effects of uncivil online debate on political polarization and expectations of deliberation. Journal of Broadcasting \& Electronic Media, 58(4), 621-633. doi: $10.1080 / 08838151.2014 .966365$

Keysar, B., Hayakawa, S. L., \& An, S. G. (2012). The foreign-language effect: Thinking in a foreign tongue reduces decision biases. Psychological Science, 23(6), 661-668. doi: $10.1177 / 0956797611432178$

Kleinke, S. (2008). Emotional commitment in public political internet message boards. Journal of Language and Social Psychology, 27(4), 409-421. doi: $10.1177 / 0261927 \times 08322483$

Knobloch-Westerwick, S., Johnson, B. K., Silver, N. A., \& Westerwick, A. (2015). Science exemplars in the eye of the beholder: How exposure to online science information affects attitudes. Science Communication, 37(5), 575-601. doi: $10.1177 / 1075547015596367$

Ladegaard, H. J. (2018). Codeswitching and emotional alignment: Talking about abuse in domestic migrant-worker returnee narratives. Language in Society, 47(5), 693-714. doi: $10.1017 / \mathrm{S} 0047404518000933$

Lee, H., \& Pang, N. (2014). Responding to the haze: Information cues and incivility in the online small world. Information Research, 19(4). Retrieved from http://www.informationr.net/ir/19-4/isic/isic04.html\#.XUA9lugzbIV 
Lemhöfer, K., \& Broersma, M. (2012). Introducing LexTALE: A quick and valid lexical test for advanced learners of English. Behavior Research Methods, 44(2), 325-343. doi: $10.3758 / \mathrm{s} 13428-011-0146-0$

List, A., \& Alexander, P. A. (2017). Cognitive affective engagement model of multiple source use. Educational Psychologist, 52(3), 182-199.

Muddiman, A., \& Stroud, N. J. (2017). News values, cognitive biases, and partisan incivility in comment sections. Journal of Communication, 67(4), 586-609. doi: $10.1111 /$ jcom. 12312

Mutz, D. C., \& Reeves, B. (2005). The new videomalaise: Effects of televised incivility on political trust. American Political Science Review, 99(1), 1-15. doi: $10.1017 / \mathrm{S} 0003055405051452$

Ng, E. W. J., \& Detenber, B. H. (2006). The impact of synchronicity and civility in online political discussions on perceptions and intentions to participate. Journal of Computer-Mediated Communication, 10(3). doi: 10.1111/j.10836101.2005.tb00252.x

Opitz, B., \& Degner, J. (2012). Emotionality in a second language: It's a matter of time. Neuropsychologia, 50(8), 1961-1967. doi: 10.1016/j.neuropsychologia.2012.04.021

O’Sullivan, P. B., \& Flanagin, A. J. (2003). Reconceptualizing 'flaming' and other problematic messages. New Media \& Society, 5(1), 69-94. https://doi.org/10.1177/1461444803005001908

Papacharissi, Z. (2002). The virtual sphere: The internet as a public sphere. New Media \& Society, 4(1), 9-27. doi: 10.1177/14614440222226244

Papacharissi, Z. (2004). Democracy online: civility, politeness, and the democratic 
potential of online political discussion groups. New Media \& Society, 6(2), 259-283. doi: $10.1177 / 1461444804041444$

Pavlenko, A. (2005). Emotions and multilingualism. Cambridge: Cambridge University Press.

Pavlenko, A. (2008). Emotion and emotion-laden words in the bilingual lexicon. Bilingualism, 11(2), 147-164. doi: 10.1017/S1366728908003283

Pavlenko, A. (2012). Affective processing in bilingual speakers: Disembodied cognition? International Journal of Psychology, 47(6), 405-428. doi: $10.1080 / 00207594.2012 .743665$

Peiser, J. (2019, $6^{\text {th }}$ February). The New York Times Co. reports $\$ 709$ million in digital Revenue for 2018. The New York Times. Retrieved from https://www.nytimes.com/2019/02/06/business/media/new-york-times-earningsdigital-subscriptions.html

Popan, J. R., Coursey, L., Acosta, J., \& Kenworthy, J. (2019). Testing the effects of incivility during internet political discussion on perceptions of rational argument and evaluations of a political outgroup. Computers in Human Behavior, 96, 123-132. doi: 10.1016/j.chb.2019.02.017

Prochazka, F., Weber, P., \& Schweiger, W. (2018). Effects of civility and reasoning in user comments on perceived journalistic quality. Journalism Studies, 19(1), 62-78. doi: 10.1080/1461670X.2016.1161497

Reese, S. D. (2010). Journalism and globalization. Sociology Compass, 4(6), 344-353. doi: 10.1111/j.1751-9020.2010.00282.x

Rösner, L., Winter, S., Walther, J. B., Krämer, N. C., \& Ganster, T. (2014, May). Lost and 
found in translation: Persuasive effects of native language and international comments on YouTube. Paper presented at the annual meeting of the International Communication Association, Seattle, WA.

Salmerón, L., Abu Mallouh, R., \& Kammerer, Y. (2017). Location of navigation menus in websites: an experimental study with Arabic users. Universal Access in the Information Society, 16(1), 191-196. doi: 10.1007/s10209-015-0444-x

Salmerón, L., Kammerer, Y., \& Delgado, P. (2018). Non-academic multiple source use on the Internet. In L. G. Braasch, I. Bråten, \& M. T. McCrudden (Eds.), Handbook of Multiple Source Use (pp. 285-302). New York: Routledge.

Sampietro, A., \& Valera-Ordaz, L. (2015). Emotional politics on Facebook. An exploratory study of Podemos' discourse during the European election campaign 2014. Recerca. Revista de Pensament i Anàlisi, 17, 61-83. Retrieved from http://www.e-revistes.uji.es/index.php/recerca/article/view/1739/1584

Sifianou, M. (2019). Im/politeness and in/civility: A neglected relationship? Journal of Pragmatics, 147, 49-64. doi: 10.1016/j.pragma.2019.05.008

Sjöberg, L. (2004). Gene Technology in the eyes of the public and experts. Moral opinions, attitudes, and risk perception. SSE/EFI Working Paper Series in Business Administration, $1-63$. Retrieved from https://swoba.hhs.se/hastba/papers/hastba2004_007.pdf

Sunstein, C. R. (2017). \#Republic: Divided democracy in the age of social media. Princeton, NJ: Princeton University Press.

Tan, K. W. P., Swee, D., Lim, C., Detenber, B. H., \& Alsagoff, L. (2008). The impact of language variety and expertise on perceptions of online political discussions. 
Journal of Computer-Mediated Communication, 13, 76-99. doi: 10.1111/j.10836101.2007.00387.x

Tenenboim, O., Chen, G. M., \& Shuning, L. (2019). Attacks in the comment sections: What it means for news sites. Retrieved from https://mediaengagement.org/attacksin-the-comment-sections

Thurman, N. (2007). The globalization of journalism online. Journalism: Theory, Practice \& Criticism, 8(3), 285-307. doi: 10.1177/1464884907076463

Tse, S. K., Yuen, A. H., Loh, E. K., Lam, J. W., \& Ng, R. H. (2010). The impact of blogging on Hong Kong primary school students' bilingual reading literacy. Australasian Journal of Educational Technology, 26(2). doi: 10.14742/ajet.1088

Tversky, A., \& Kahneman, D. (1981). The framing of decisions and the psychology of choice. Science, 211(4481), 453-458. doi: 10.1126/science.7455683

Walther, J. B., Neubaum, G., Rösner, L., Winter, S., \& Krämer, N. C. (2018). The effect of bilingual congruence on the persuasive influence of videos and comments on YouTube. Journal of Language and Social Psychology, 37(3), 310-329. doi: $10.1177 / 0261927 \times 17724552$

Widholm, A. (2019). Transnational news consumption and digital content mobility. Journalism Studies, 20(10), 1472-1490. doi: 10.1080/1461670X.2018.1526642

Williams, A., Srinivasan, M., Liu, C., Lee, P., \& Zhou, Q. (2019). Why do bilinguals codeswitch when emotional? Insights from immigrant parent-child interactions. Emotion. doi: $10.1037 / \mathrm{emo} 0000568$

Yakut, A. D., \& Aydın, S. (2017). An experimental study on the effects of the use of blogs on EFL reading comprehension. Innovation in Language Learning and Teaching, 
[Paper currently under review - please do not cite without authors' permission]

11(1), 1-16. doi: 10.1080/17501229.2015.1006634 


\section{Tables}

Table 1. Arguments about the risks and benefits of the topics discussed in the news reports and in the online comments used in Study 1.

\begin{tabular}{|l|l|l|l|}
\hline \multirow{2}{*}{ Topic } & \multicolumn{2}{|c|}{ Text } & \multicolumn{1}{c|}{ Comment } \\
\cline { 2 - 4 } & \multicolumn{1}{|c|}{ Risks } & \multicolumn{1}{c|}{ Benefits } & Additional argument \\
\hline Biofuels & $\begin{array}{l}\text { Biofuels } \\
\text { production } \\
\text { smpacts food } \\
\text { supplies }\end{array}$ & $\begin{array}{l}\text { Biofuels } \\
\text { improve air } \\
\text { quality }\end{array}$ & $\begin{array}{l}\text { Biofuels production } \\
\text { damages the } \\
\text { environment } \\
\text { (deforestation, } \\
\text { emissions })\end{array}$ \\
\hline Nanotechnology & $\begin{array}{l}\text { Airborne } \\
\text { nanoparticles are } \\
\text { toxic }\end{array}$ & $\begin{array}{l}\text { Nanotechnology } \\
\text { offers } \\
\text { outstanding } \\
\text { medical } \\
\text { capabilities }\end{array}$ & $\begin{array}{l}\text { Nanotechnology can } \\
\text { be used to strengthen } \\
\text { heart tissues }\end{array}$ \\
\hline
\end{tabular}


Table 2. Attitude change towards the view described in the comment, by language (L1 vs. L2) and comment civility (civil vs. uncivil) (number of participants).

\begin{tabular}{|l|l|l|l|l|}
\hline \multirow{2}{*}{} & \multicolumn{2}{|c|}{ L1 (Spanish) } & \multicolumn{2}{c|}{ L2 (English) } \\
\cline { 2 - 5 } & \multicolumn{1}{|c|}{ Civil } & \multicolumn{1}{c|}{ Uncivil } & Civil & Uncivil \\
\hline $\begin{array}{l}\text { Change } \\
\text { towards } \\
\text { comment }\end{array}$ & $50 \%(16)$ & $18.4 \%(7)$ & $47.3 \%(18)$ & $31.2 \%(10)$ \\
\hline $\begin{array}{l}\text { No attitude } \\
\text { change }\end{array}$ & $46.8 \%(15)$ & $60.5 \%(23)$ & $39.5 \%(15)$ & $56.2 \%(18)$ \\
\hline $\begin{array}{l}\text { Change against } \\
\text { comments }\end{array}$ & $3.1 \%(1)$ & $21.1(8)$ & $13.2 \%(5)$ & $12.5 \%(4)$ \\
\hline
\end{tabular}


Table 3. Distribution of tweets by language, civility, and supported position, in each condition of study 2.

\begin{tabular}{|l|l|l|l|l|l|l|}
\hline Condition & Language & $\begin{array}{l}\text { Civil } \\
\text { pro- } \\
\text { topic } \\
\text { tweets }\end{array}$ & $\begin{array}{l}\text { Civil } \\
\text { against- } \\
\text { topic } \\
\text { tweets }\end{array}$ & $\begin{array}{l}\text { Uncivil } \\
\text { pro- } \\
\text { topic } \\
\text { tweets }\end{array}$ & $\begin{array}{l}\text { Uncivil } \\
\text { against- } \\
\text { topic } \\
\text { tweets }\end{array}$ & $\begin{array}{l}\text { Neutral } \\
\text { tweets }\end{array}$ \\
\hline $\begin{array}{l}\text { Civil pro-topic in } \\
\text { an L1 }\end{array}$ & L1 & 8 & 2 & 2 & 8 & 5 \\
\hline $\begin{array}{l}\text { Civil pro-topic in } \\
\text { an L2 }\end{array}$ & L2 & 8 & 2 & 2 & 8 & 5 \\
\hline $\begin{array}{l}\text { Civil against- } \\
\text { topic in an L1 }\end{array}$ & L1 & 2 & 8 & 8 & 2 & 5 \\
\hline $\begin{array}{l}\text { Civil against- } \\
\text { topic in an L2 }\end{array}$ & L2 & 2 & 8 & 8 & 2 & 5 \\
\hline
\end{tabular}


Table 4. Attitude change towards the view described in the comment, by language (L1 vs. L2) and discussion civility (civil pro-topic vs. uncivil pro-topic) (Number of participants).

\begin{tabular}{|l|l|l|l|l|}
\hline \multirow{2}{*}{} & \multicolumn{2}{|c|}{ L1 (Spanish) } & \multicolumn{2}{c|}{ L2 (English) } \\
\cline { 2 - 5 } & \multicolumn{1}{|c|}{ Civil } & \multicolumn{1}{c|}{ Uncivil } & \multicolumn{1}{c|}{ Civil } & Uncivil \\
\cline { 2 - 5 } & Pro-topic & \multicolumn{1}{|c}{ Pro-topic } & Pro-topic & Pro-topic \\
\hline $\begin{array}{l}\text { Change } \\
\text { towards pro- } \\
\text { topic }\end{array}$ & $61.9 \%(13)$ & $19.0 \%(4)$ & $42.8 \%(9)$ & $47.6 \%(10)$ \\
\hline $\begin{array}{l}\text { No attitude } \\
\text { change }\end{array}$ & $14.3 \%(3)$ & $28.6 \%(6)$ & $4.7 \%(1)$ & $9.5 \%(2)$ \\
\hline $\begin{array}{l}\text { Change against } \\
\text { pro-topic }\end{array}$ & $23.8 \%(5)$ & $52.4 \%(11)$ & $52.4 \%(11)$ & $42.8 \%(9)$ \\
\hline
\end{tabular}

